Pacific Journal of Mathematics

THE REGULAR OPEN CONTINUOUS IMAGES OF COMPLET 


\title{
THE REGULAR OPEN CONTINUOUS IMAGES OF COMPLETE METRIC SPACES
}

\author{
How ARD H. WICKE
}

\begin{abstract}
This article characterizes the regular $T_{0}$ open continuous images of complete metric spaces. These images are shown to be the regular $T_{0}$-spaces having monotonically complete bases of countable order. This follows from a theorem of Worrell and Wicke and a theorem below which shows that every regular $T_{0}$-space having a monotonically complete base of countable order is an open continuous image of a complete metric space.
\end{abstract}

The class of regular $T_{0}$-spaces having monotonically complete bases of countable order is equivalent to a class of spaces Aronszajn introduced axiomatically in [4]. This class includes the complete metric spaces and spaces satisfying R. L. Moore's Axiom 1 [9]. Theorem 2 provides contrast to the theorem of Ponomarev [10]: every $T_{0}$ first countable space is an open continuous image of a metric space. A result related to Theorem 3 is Arhangel'skil's characterization of the $T_{1}$ open compact continuous images of metrizable spaces as the metacompact developable $T_{1}$-spaces [2]. In connection with this result, it may be noted that an open compact continuous $T_{1}$ image of a regular $T_{0}$-space having a base of countable order also has a base of countable order [11], and a $T_{1}$ metacompact space having a base of countable order is developable [12].

For notation and terminology the reader is referred to [7], [9], and [12]. Space is used here to mean topological space. The null set convention is not used. A base for the topology of a space $S$ will be referred to as a base for $S$. Recall that a collection of sets is said to be perfectly decreasing [12], if and only if each of its elements properly includes an element of the collection; and that a base of countable order for a space [3], can be defined as a base $B$ for the space such that if $P$ is a point common to the elements of a perfectly decreasing subcollection $K$ of $B$, any open set containing $P$ includes an element of $K$; i.e., the elements of $K$ form a base at $P$. By a monotonically complete base [11], is meant a base $B$ such that the closures of the elements of any monotonic subcollection of $B$ have a point in common. Recall also that regular $T_{0}$-spaces are $T_{1}$, as Koutský remarked [5, p. 826]. 
2. Regular spaces having monotonically complete bases of countable order.

THEOREM 1. A regular $T_{0}$-space $S$ has a monotonically complete base of countable order if and only if there exists a sequence $G_{1}, G_{2}, \cdots$ of bases for the topology of $S$ such that if $g_{1}, g_{2}, \cdots$ is a sequence such that, for each $n, g_{n}$ belongs to $G_{n}$ and $\bar{g}_{n+1}$ is a subset of $g_{n}$, then there exists a point $P$ in each $g_{n}$ such that the collection of terms of $g_{1}, g_{2}, \cdots$ is a base at $P$.

Proof. Suppose $V$ is a monotonically complete base of countable order for $S$. There exists a sequence $H_{1}, H_{2}, \cdots$ of well-ordered subcollections of $V$ covering $S$ such that these conditions are satisfied:

(1) For each $n$ and $h$ in $H_{n}$ there exists a point $P_{n, h}$ belonging to $h$ such that no element of $H_{n}$ precedes $h$ and contains $P_{n, n}$.

(2) If $n<k$, the closure of the first element $h$ of $H_{k}$ containing the point $P$ is a subset of the first element $h^{\prime}$ of $H_{n}$ containing $P$; and if $P$ is in a proper subset of $h^{\prime}, \bar{h}$ is a proper subset of $h^{\prime}$. By an argument similar to that used in the proof of Theorem 1 of [12], it follows that the collections $G_{n}=H_{n}+H_{n+1}+\cdots$ are bases for $S$. If $g_{1}, g_{2}, \cdots$ is a sequence as in the statement of Theorem 1, there exists a first $h_{n}$ in $H_{n}$ that includes a term of $g_{1}, g_{2}, \ldots$. For each $n$, there exists $j>n+1$ such that $g_{j}$ is a subset of $h_{n}$ and $h_{n+1}$. For some $k \geqq j, g_{j}$ belongs to $H_{k}$. Let $P$ denote the point $P_{k, q_{j}}$. If $h$ is the first element of $H_{n}$ to contain $P$ then $h$ includes $g_{j}$. Thus $h$ does not precede $h_{n}$. Since $h_{n}$ contains $P$ it follows that $h=h_{n}$. Similarly, $h_{n+1}$ is the first element of $H_{n+1}$ to contain $P$ and thus $\bar{h}_{n+1}$ is a subset of $h_{n}$. If $h_{n}=h_{n+1}$ for some $n$, then $h_{n}=\{P\}$ for some point $P$, and thus $g_{k}=\{P\}$ for some $k$, and $\left\{g_{k}\right\}$ is a base at $P$. If $h_{n} \neq h_{n+1}$, for any $n$, the terms of $h_{1}, h_{2}, \cdots$ form a monotonic subcollection of $V$ and thus there exists a point $P$ common to each $\bar{h}_{n}$. Since $\bar{h}_{n+1}$ is a subset of $h_{n}, P$ is in each $h_{n}$. If $D$ is open and contains $P$, there exists some $h_{n}$ which is a subset of $D$ and thus some $g_{k}$ is included in $D$. Hence $P$ is in $\bar{g}_{k}$ for all $k$, and since $\bar{g}_{k}$ is a subset of $g_{k-1}$ for all $k>1$, it follows that $P$ is in each $g_{k}$. Since the $h_{n}$ 's form a base at $P$ so do the $g_{n}$ 's.

If $G_{1}, G_{2}, \cdots$ is a sequence as in the statement of Theorem 1 there exists a sequence $H_{1}, H_{2}, \cdots$ of well-ordered collections covering $S$ such that for each $n$ : (1) $H_{n}$ is a subcollection of $G_{n}$. (2) Each element $h$ of $H_{n}$ contains a point belonging to no predecessor of $h$ in $H_{n}$. (3) If $n<k$ and $P$ is a point, the closure of the first element of $H_{k}$ containing $P$ is a subset of the first element of $H_{n}$ doing so. $V=$ $H_{1}+H_{2}+\cdots$ is a base for $S$ and can be shown to be a base of 
countable order by an argument used in Theorem 2 of [12]. A technique similar to one employed there and álso in the preceding paragraph, shows that $V$ is monotonically complete.

THEOREM 2. A regular $T_{0}$-space having a monotonically complete base of countable order is an open continuous image of a complete metric space.

Proof. Let $S$ denote a regular $T_{0}$-space having a monotonically complete base of countable order. By Theorem 1 there exists a sequence $G_{1}, G_{2}, \cdots$ of bases for $S$ with the property stated in that theorem. Form the Baire space $M[6]$ over the collections $G_{1}, G_{2}, \ldots$. The elements of $M$ are sequences $\xi=\left(g_{1}, g_{2}, \cdots\right)$ where $g_{n}$ belongs to $G_{n}$. If $\xi=\left(g_{1}, g_{2}, \cdots\right)$ and $\xi^{\prime}=\left(g_{1}^{\prime}, g_{2}^{\prime}, \cdots\right)$ the distance $\rho\left(\xi, \xi^{\prime}\right)$ is defined to be $1 / k$ if there exists a first positive integer $k$ such that $g_{k} \neq g_{k}^{\prime}$. Otherwise $\rho\left(\xi, \xi^{\prime}\right)=0$. Designate by $O_{a_{1} \cdots a_{k}}$ the collection of all sequences $\left(a_{1}^{\prime}, a_{2}^{\prime}, \cdots\right)$ such that $a_{i}=a_{i}^{\prime}, i=1, \cdots, k$. Let $W$ denote the collection of all elements in $M$ of the form $\left(g_{1}, g_{2}, \ldots\right)$ where for each $n, \bar{g}_{n+1}$ is a subset of $g_{n}$. Then, by the condition on $G_{1}, G_{2}, \cdots$, there exists a unique point $P$ common to the terms of $g_{1}, g_{2}, \ldots$. If $\xi=\left(g_{1}, g_{2}, \cdots\right)$ is in $W$, define $f \xi$ to be the unique point $P$ common to the $g_{n}$ 's. If $P$ is a point of $S$, by regularity there exists an element $\xi$ of $W$ such that $P$ is common to the terms of $\xi$. Hence $f$ is a mapping of $W$ onto $S$. Suppose $W$ intersects the set $O_{g_{1} \cdots g_{k}}$. Then $\bar{g}_{i \div 1}$ is a subset of $g_{i}$ for all $i \leqq k-1$. Clearly, $f\left(W \cdot O_{g_{1} \cdots g_{k}}\right)$ is a subset of $g_{k}$. If $P$ is an element of $g_{k}$, there exists $g_{k+1}, g_{k+2}, \cdots$ such that $\bar{g}_{k+n}$ is a subset of $g_{k+n-1}$ for all $n \geqq 1$. Hence $f\left(W \cdot O_{g_{1} \cdots g_{k}}\right)=$ $g_{k}$. Since the collection of all sets $W \cdot O_{g_{1} \cdots g_{k}}$ is a base for $W$ and by the property of $G_{1}, G_{2}, \cdots, f$ is open and continuous on $W$. (This argument is related to one used by Ponomarev [10].)

Suppose $P_{1}, P_{2}, \cdots$ is a sequence of points of $W$ satisfying the Cauchy convergence criterion. For each $n$, there exists a positive integer $m_{n}$ such that $\rho\left(P_{k}, P_{j}\right)<1 / n$, provided $k, j \geqq m_{n}$. It may be assumed that $m_{n+1}>m_{n}$ for every $n$. Let $a_{1}^{n}, a_{2}^{n}, \cdots, a_{n}^{n}$ denote the first $n$ coordinates of $P_{m_{n}}$. Let $a_{n}$ denote $a_{n}^{n}$ for each $n$. Then if $k \geqq m_{n}$, the first $n$ coordinates of $P_{k}$ are $a_{1}, \cdots, a_{n}$. For if $n=1$, $a_{1}=a_{1}^{1}$ is the first coordinate of $P_{m_{1}}$. If $k>m_{1}$, then $\rho\left(P_{k}, P_{m_{1}}\right)<1$, and thus $a_{1}$ is the first coordinate of $P_{k}$. Suppose the statement is true for $n$. If $k \geqq m_{n+1}$, then $\rho\left(P_{k}, P_{m_{n+1}}\right)<1 /(n+1)$. Since $m_{n \div 1}>m_{n}$, the first $n$ coordinates of $P_{m_{n+1}}$ are $a_{1}, \cdots, a_{n}$, by the assumption, and the $(n+1)^{\text {st }}$ coordinate is $a_{n+1}$. Let $P$ denote $\left(a_{1}, a_{2}, \cdots\right)$. It follows that $P$ is the sequential limit point of $P_{1}, P_{2}, \ldots$. Moreover, since $P_{m_{n}}$ is in $W$, the coordinates $a_{1}, a_{2}, \cdots, a_{n}$ satisfy the condition 
that $\bar{a}_{k+1}$ is a subset of $a_{k}$ for all $k \leqq n-1$. Since this is true for all $n$, it follows that $P$ is in $W$, and thus $W$ is complete with respect to $\rho$.

REMARK. From the proof of the above theorem it may be seen that the complete metric space of the theorem may be taken to be of zero dimension and of the same weight as the image space. (The weight of a topological space is the minimum cardinal number $m$ such that the space has a base of power $m[1]$.)

3. The characterization theorem. In [11] Worrell and Wicke define a $\lambda$-base for a topological space as a base $B$ of countable order for the space such that if $K$ is a perfectly decreasing monotonic subcollection of $B$, there exists a point $P$ such that any open set containing $P$ includes an element of $K$. A regular $T_{0}$-space has a $\lambda$-base if and only if it has a monotonically complete base of countable order [11]. A principal theorem of [11] is that an open continuous (essentially) $T_{1}$ image of a space having a $\lambda$-base also has a $\lambda$-base.

THEOREM 3. A regular $T_{0}$-space is an open continuous image of a complete metric space if and only if it has a monotonically complete base of countable order.

Proof. The sufficiency follows from Theorem 2. The necessity is a consequence of the theorems cited in the paragraph preceding the statement of Theorem 3, and the facts that a regular $T_{0}$-space is $T_{1}$ and that a complete metric space has a $\lambda$-base.

THEOREM 4. The following conditions on a regular $T_{0}$-space are equivalent.

(a) The space has a monotonically complete base of countable order.

(b) The space satisfies Aronszajn's axiom [4, p. 231].

(c) The space has a $\lambda$-base.

(d) The space is an open continuous image of a complete metric space.

Proof. The equivalence of (a), (b), and (c) is stated in [11], and may be established by methods used in the proof of Theorem 1 above. Theorem 3 above shows the equivalence of (a) and (d).

By using techniques similar to those used above, the following theorem may be proved. (The sufficiency is a joint result of Worrell and Wicke given in [11].) 
THeOREM 5. A $T_{1}$-space $S$ has a base of countable order if and only if there exists a metric space $(M, d)$ and an open continuous mapping $f$ of $M$ onto $S$ such that for each $x$ in $S, f^{-1}(x)$ is complete with respect to the metric $d$.

This result and a theorem of Arhangel'skil [3] imply the following theorem of Michael [8]:

If $f$ is an open continuous mapping of a metric space $E$ onto a $T_{2}$ paracompact space $F$ such that $f^{-1}(y)$ is complete for every $y$ in $F$, then $F$ is metrizable.

\section{REFERENCES}

1. P. S. Alexandroff and P. Urysohn, Mémoire sur les espaces topologiques compacts, Verh. Nederl. Akad. Wetensch. Afd. Natuurk. 14 (1929), 1-96.

2. A. Arhangel'skiľ, On mappings of metric spaces, Soviet Math. Dokl. 3 (1962), 953-956; translation of Dokl. Akad. Nauk SSSR 145 (1962), 245-248.

3. - - Some metrization theorems, Uspehi Mat. Nauk (113) 18 (1963), 139-145, (Russian). 4. N. Aronszajn, Über die Bogenverknüpfung in topologischen Räumen, Fund. Math. 15 (1930), 228-241.

5. E. Čech, On bicompact spaces, Ann. of Math. 38 (1937), 823-844.

6. F. Hausdorff, Mengenlehre, Berlin-Leipzig, 3rd ed., 1935.

7. J. L. Kelley, General Topology, Princeton, 1955.

8. E. Michael, $A$ theorem on semi-continuous set-valued functions, Duke Math. J. 27 (1959), 647-651.

9. R. L. Moore, Foundations of Point Set Theory, Revised Edition, Amer. Math. Soc. Coll. Pub. XIII (1962).

10. V. I. Ponomarev, Axioms of countability and continuous mappings, Bull. Polon. Acad. Sci., Sér. Sci. Math. Astron. \& Phys. 7 (1960), 127-133, (Russian).

11. H. H. Wicke and J. M. Worrell, Jr., Open continuous mappings of spaces having bases of countable order, Abstract 628-4, Notices of the Amer. Math. Soc. 12 (1965), 803. (To appear in Duke Math. J. 1967.)

12. J. M. Worrell, Jr. and H. H. Wicke, Characterizations of developable topological spaces, Canad. J. Math. 17 (1965), 820-830.

Received August 23, 1966. This work was supported by the United States Atomic Energy Commission.

SANDIA LABORATORY

Albuquerque, New Mexico 



\section{PACIFIC JOURNAL OF MATHEMATICS}

\section{H. ROYDEN}

Stanford University

Stanford, California

\author{
J. P. JANS \\ University of Washington \\ Seattle, Washington 98105
}

\section{EDITORS}

\author{
J. DugundJI \\ Department of Mathematics \\ Rice University \\ Houston, Texas 77001 \\ Richard ARENS \\ University of California \\ Los Angeles, California 90024
}

\section{ASSOCIATE EDITORS}
E. F. BECKENBACH
B. H. NeumanN
F. WOLF
K. YOSIDA

\section{SUPPORTING INSTITUTIONS}

\author{
UNIVERSITY OF BRITISH COLUMBIA \\ CALIFORNIA INSTITUTE OF TECHNOLOGY \\ UNIVERSITY OF CALIFORNIA \\ MONTANA STATE UNIVERSITY \\ UNIVERSITY OF NEVADA \\ NEW MEXICO STATE UNIVERSITY \\ OREGON STATE UNIVERSITY \\ UNIVERSITY OF OREGON \\ OSAKA UNIVERSITY \\ UNIVERSITY OF SOUTHERN CALIFORNIA
}

\author{
STANFORD UNIVERSITY \\ UNIVERSITY OF TOKYO \\ UNIVERSITY OF UTAH \\ WASHINGTON STATE UNIVERSITY \\ UNIVERSITY OF WASHINGTON \\ AMERICAN MATHEMATICAL SOCIETY \\ CHEVRON RESEARCH CORPORATION \\ TRW SYSTEMS \\ NAVAL ORDNANCE TEST STATION
}

Mathematical papers intended for publication in the Pacific Journal of Mathematics should be typewritten (double spaced). The first paragraph or two must be capable of being used separately as a synopsis of the entire paper. It should not contain references to the bibliography. Manuscripts may be sent to any one of the four editors. All other communications to the editors should be addressed to the managing editor, Richard Arens at the University of California, Los Angeles, California 90024.

50 reprints per author of each article are furnished free of charge; additional copies may be obtained at cost in multiples of 50 .

The Pacific Journal of Mathematics is published monthly. Effective with Volume 16 the price per volume (3 numbers) is $\$ 8.00$; single issues, $\$ 3.00$. Special price for current issues to individual faculty members of supporting institutions and to individual members of the American Mathematical Society: $\$ 4.00$ per volume; single issues $\$ 1.50$. Back numbers are available.

Subscriptions, orders for back numbers, and changes of address should be sent to Pacific Journal of Mathematics, 103 Highland Boulevard, Berkeley 8, California.

Printed at Kokusai Bunken Insatsusha (International Academic Printing Co., Ltd.), 7-17, Fujimi 2-chome, Chiyoda-ku, Tokyo, Japan.

PUBLISHED BY PACIFIC JOURNAL OF MATHEMATICS, A NON-PROFIT CORPORATION

The Supporting Institutions listed above contribute to the cost of publication of this Journal, but they are not owners or publishers and have no responsibility for its content or policies. 


\section{Pacific Journal of Mathematics}

A. A. Aucoin, Diophantine systems ............................. 419

Charles Ballantine, Products of positive definite matrices. I ............... 427

David Wilmot Barnette, A necessary condition for d-polyhedrality ............ 435

James Clark Beidleman and Tae Kun Seo, Generalized Frattini subgroups of finite groups ......................................... 441

Carlos Jorge Do Rego Borges, A study of multivalued functions ............. 451

William Edwin Clark, Algebras of global dimension one with a finite ideal

lattice ...............................................

Richard Brian Darst, On a theorem of Nikodym with applications to weak convergence and von Neumann algebras .........................

George Wesley Day, Superatomic Boolean algebras .....................

Lawrence Fearnley, Characterization of the continuous images of all

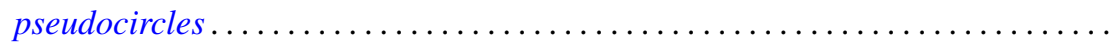

Neil Robert Gray, Unstable points in the hyperspace of connected subsets....... 515

Franklin Haimo, Polynomials in central endomorphisms .................. 521

John Sollion Hsia, Integral equivalence of vectors over local modular lattices . . . . 527

Jim Humphreys, Existence of Levi factors in certain algebraic groups .......... 543

E. Christopher Lance, Automorphisms of postliminal $C^{*}$-algebras ............ 547

Sibe Mardesic, Images of ordered compacta are locally peripherally metric . . . . 557

Albert W. Marshall, David William Walkup and Roger Jean-Baptiste Robert Wets,

Order-preserving functions: Applications to majorization and order

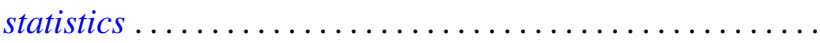

Wellington Ham Ow, An extremal length criterion for the parabolicity of

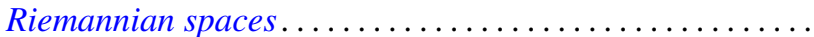

585

Wellington Ham Ow, Criteria for zero capacity of ideal boundary components of

Riemannian spaces...................................... 591

J. H. Reed, Inverse limits of indecomposable continua .................. 597

Joseph Gail Stampfli, Minimal range theorems for operators with thin spectra . . . 601

Roy Westwick, Transformations on tensor spaces..................... 613

Howard Henry Wicke, The regular open continuous images of complete metric

spaces ........................................... 621

Abraham Zaks, A note on semi-primary hereditary rings .............. 627

Thomas William Hungerford, Correction to: "A description of $\operatorname{Mult}_{i}\left(A^{1}, \cdots, A^{n}\right)$

by generators and relations" ............................. 629

Uppuluri V. Ramamohana Rao, Correction to: "On a stronger version of Wallis' formula".............................................. 629

Takesi Isiwata, Correction: "Mappings and spaces" ................... 630

Henry B. Mann, Josephine Mitchell and Lowell Schoenfeld, Correction to:

"Properties of differential forms in $n$ real variables" .... . .

James Calvert, Correction to: "An integral inequality with applications to the

Dirichlet problem"............................. 